D) Check for updates

Cite this: Dalton Trans., 2020, 49, 2331

Received 16th January 2020 , Accepted 23rd January 2020

DOI: $10.1039 / \mathrm{d} 0 \mathrm{dt} 00183 \mathrm{j}$

rsc.li/dalton

\title{
A designed and potentially decadentate ligand for use in lanthanide(III) catalysed biomass transformations: targeting diastereoselective trans-4,5-diaminocyclopentenone derivatives $\uparrow$
}

\author{
Krisana Peewasan, (D) *a Marcel P. Merkel, (iD) ${ }^{b}$ Olaf Fuhr (DD ${ }^{b, c}$ and \\ Annie K. Powell (D) *a,b
}

\begin{abstract}
The goal of this study was to design a ligand system which can accommodate single lanthanide(III)-ions and investigate the properties of the resulting complexes. The complexes of all the accesible lanthanides and yttrium with the new ligand $\mathbf{L H}_{6}=N, N^{\prime}$-dimethyl- $N, N^{\prime}$-ethylene-bis(5-bromo-3-(1H-benzimidazol2-yl)hydrazineylidene)-2-hydroxybenzylamine) were obtained in high yield at room temperature under aerobic reaction conditions. The corresponding compounds were characterised using X-ray diffraction, FT-IR, elemental analysis and the optical properties of all complexes were investigated using UV-vis and fluorescence spectroscopy. The air stable complexes efficiently transform biomass furfural to trans4,5-cyclopentenones in high yield.
\end{abstract}

\section{Introduction}

Recently the importance of using lanthanide complexes as catalysts in organic reactions ${ }^{1-4}$ and enzymatic processes has been recognised. ${ }^{5}$ The properties of lanthanide coordination complexes include (i) electronic and magnetic properties (ii) usually small ligand field but large spin-orbit coupling effects (iii) large coordination numbers and adaptable coordination geometry, both of which are desirable for catalytic applications (iv) a preference for hard donor ligands for oxidation state III as well as high Lewis acidity. This latter point is illustrated by the investigations carried out in natural synthesis reactions for e.g. prostaglandins, prostanoid derivatives, and a range of bioactive molecules. ${ }^{6-12}$ A particular example of interest to us, is the transformation of furfural to asymmetric bifunctionalized

\footnotetext{
${ }^{a}$ Institute of Inorganic Chemistry, Karlsruhe Institute of Technology, Engesserstrasse 15, 76131 Karlsruhe, Germany. E-mail: krisana.peewasan@kit.edu, annie.powell@kit.edu

${ }^{b}$ Institute of Nanotechnology, Karlsruhe Institute of Technology Campus North, Hermann-von-Helmholtz-Platz 1, 76344 Eggenstein-Leopoldshafen Karlsruhe, Germany.E-mail: marcel.merkel@kit.edu, olaf.fuhr@kit.edu, annie.powell@kit.edu ${ }^{c}$ Karlsruhe Nano Micro Facility Karlsruhe Institute of Technology,

Hermann-von-Helmholtz-Platz 1, 76344 Eggenstein-Leopoldshafen, Germany.

E-mail: olafffuhr@kit.edu

$\dagger$ Electronic supplementary information (ESI) available: Experimental section, X-ray structure determinations, elemental analysis (CHN), NMR spectra, IR spectra, UV-vis spectra and CIFs of complexes $\mathbf{S m L H}_{6}, \mathbf{Y b L H}_{6}, \mathbf{E r L H}_{\mathbf{6}}$ and $\mathbf{Y L H}_{\mathbf{6}}$. CCDC 1956883, 1939447, 1956884 and 1956885. For ESI and crystallographic data in CIF or other electronic format see DOI: 10.1039/d0dt00183j
}

trans-4,5-diaminocyclopentenones through addition of appropriate amines with the help of promoters (Fig. 1). In such a way, furfural, which is readily available from biomass, produced from corncobs, bagasse, etc. ${ }^{13}$ These structural motifs are versatile building blocks for the retrosynthetic pathway of $(-)$-agelastatin $A,{ }^{12}$ an architecturally unique cytotoxic tetracyclic alkaloid first isolated from the axinellid sponge Agelas dendromorpha. ${ }^{14,15}$

Over the past 20 years the transformation of furfural available from biomass to diastereoselective cyclopentenones has been intensively developed and investigated. Batey and coworkers was first reported the utilisation of $\operatorname{Dy}(\mathrm{OTf})_{3}$ as Lewis acid to catalyse a domino condensation/ring-opening/electrocyclization process. $^{6}$ This pioneer study led to an increasing number of alternative strategies for the formation of trans4,5-diamino-cyclopent-2-enone derivatives such as the employment of the ionic liquid 1-methylimidazolium tetrafluoroborate, ${ }^{16}$ tosylamine metal free catalyst, ${ }^{17} \mathrm{Al}(\mathrm{Cl})_{3},{ }^{18} 3 \mathrm{~d} / 4 \mathrm{f}-$ clusters, ${ }^{19,20} \mathrm{ErCl}_{3}{ }^{10}$ or $\mathrm{ErCl}_{3}$ immobilized on silica, ${ }^{21}$ under microwave irradiation ${ }^{22}$ and $\mathrm{Cu}(\mathrm{OTf})_{2}$ in water as a reusable catalyst. ${ }^{23}$ A recent report from Batey and co-workers revealed the efficiency of the Dy $(\mathrm{OTf})_{3}$ catalyst for the transformation of

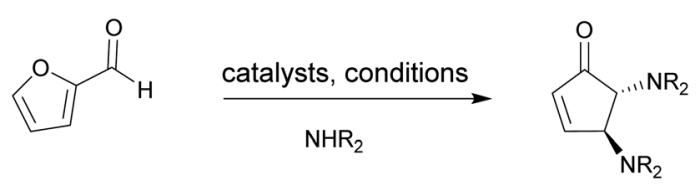

Fig. 1 Transformation of furfural to a trans-4,5-diaminocyclopentenone. 
the substituted furfuraldehydes to 3-substituted-trans-4,5cyclopentenone in high stereoselectively and yield. ${ }^{11}$ Herein a new family of lanthanide(III)-complexes was prepared and the resulting compounds were characterised using X-ray diffraction, FT-IR, elemental analysis and spectroscopy and their catalytic properties were investigated. We designed the ligand $\mathbf{L H}_{\mathbf{6}}=\left(N, N^{\prime}\right.$-dimethyl- $N, N^{\prime}$-ethylene-bis(5-bromo-3-(1H-benzimidazol-2-yl)hydrazineylidene)-2-hydroxybenzyl amine) which contains the previously used acetato-diphenoxoamine building block (1). ${ }^{24}$ The complexations of the corresponding ligand with all available $\mathrm{Ln}^{3+}$ and $\mathrm{Y}^{3+}$ ions were performed. In addition, the catalytic properties of these complexes for transformation of furfuran to trans-4,5-diamino-cyclopent-2-enone under various reaction conditions were investigated.

\section{Results and discussion}

\section{Synthesis}

The novel ligand $\mathbf{L H}_{\mathbf{6}}$ was prepared by the condensation reaction of $N, N^{\prime}$-dimethyl- $N, N^{\prime}$-ethylenedi(5-bromo-3-formyl-2-hydroxybenzyl amine (1) and 2-hydrazino-1H-1,3-benzimidazole (2) (Fig. 2).

The Ln(III)-complexes were obtained in high yield by the reaction of ligand $\mathbf{L H}_{6}$ with appropriate $\mathrm{Ln}\left(\mathrm{NO}_{3}\right)_{3} \cdot \mathrm{H}_{2} \mathrm{O}$ salts in the ratio $1: 1$ in a mixture of acetonitrile and methanol $(1: 1$, $\% \mathrm{v} / \mathrm{v}$ ) at room temperature in air for $30 \mathrm{~min}$. After standing for 7 days, crystal products were collected by filtration. The product could be also directly obtained in the form of powder in higher yield by rapid and prolonged stirring for up to $2 \mathrm{~h}$. The powder adducts were characterised using elemental analysis, IR, UV-vis, fluorescence spectroscopy and Powder X-ray Diffraction (PXRD) (see ESI $\dagger$ ).

\section{Crystal structures}

The single crystal X-ray data shows that two classes of lanthanide complexes were obtained using the same reaction conditions. The first family (lanthanum to holmium) was found to have 10-fold coordination and the second family (erbium to lutetium) has 8 -fold coordination (Fig. 3). This reflects the fact that the atomic radii of lanthanides decrease from lanthanum to lutetium. Additionally, the complexation of yttrium with the same ligand was also investigated. As expected the Y(III) has 10 -fold coordination given that the atomic radius of $\mathrm{Y}$ (III) lies
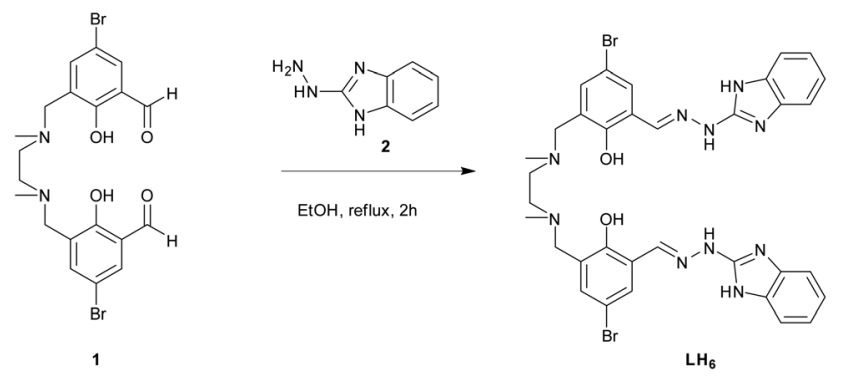

Fig. 2 Preparation of Schiff-base ligand $\mathrm{LH}_{6}$.
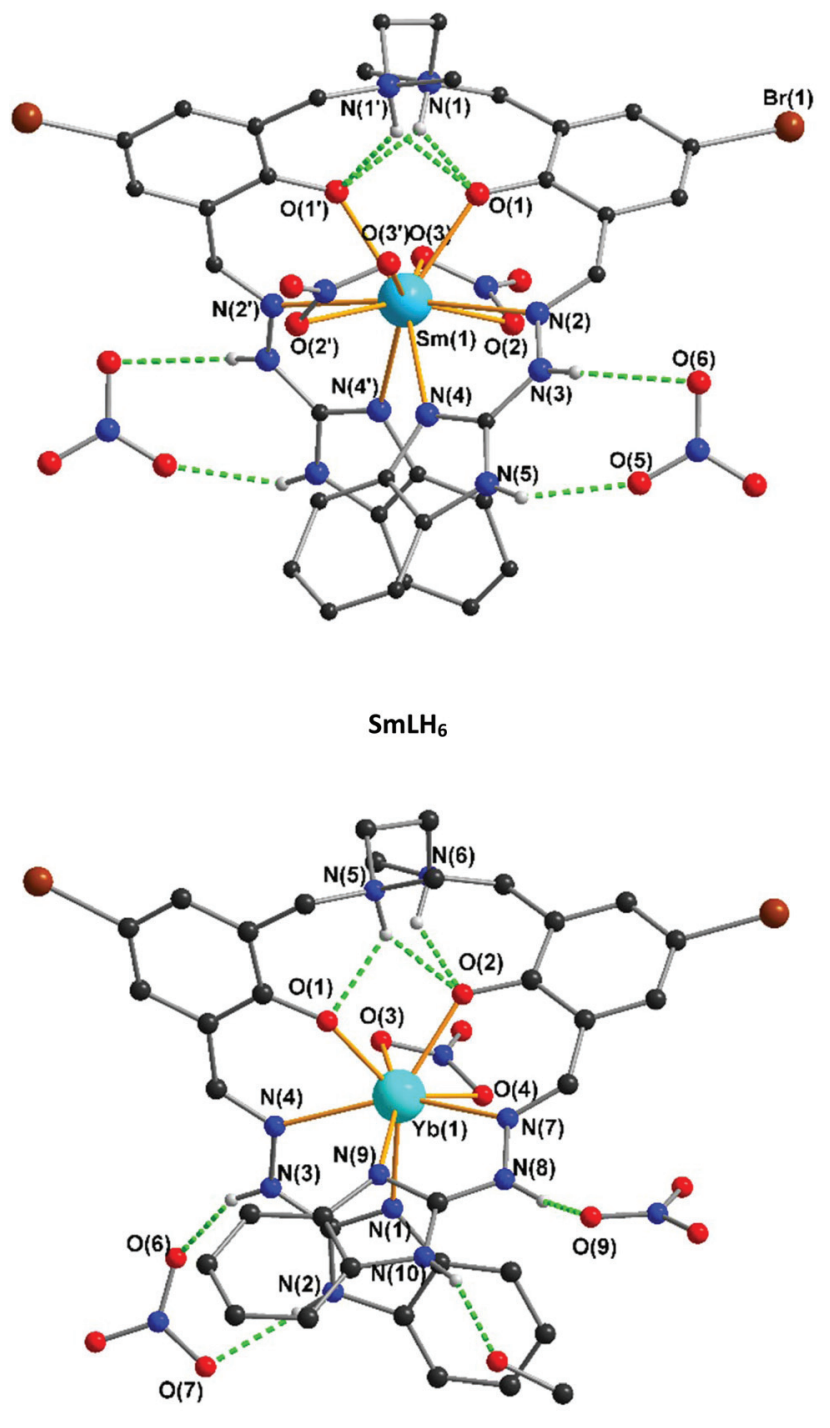

$\mathrm{YbLH}_{6}$

Fig. 3 The structure of $\mathrm{SmLH}_{6}$ and $\mathrm{YbLH}_{6}$. Colour codes for the atoms: light blue ( $\mathrm{Sm}$ and $\mathrm{Yb}$ ), blue $(\mathrm{N})$, red $(\mathrm{O})$ black $(\mathrm{C})$ and brown $(\mathrm{Br})$. The hydrogen bonds are highlighted in green dashed line. Solvent molecules $(\mathrm{MeCN})$ in lattice and $\mathrm{H}$ atoms are omitted for clarity.

between that of Dy(III) and Ho(III) (Fig. S34†). The characterization of the powder sample using PXRD confirmed the isostructural nature for family one by comparison with the $\mathbf{S m L H}_{6}$ or family two with $\mathbf{Y b L H}_{\mathbf{6}}$ (Fig. 4). Regarding the first class of this system $\mathbf{S m L H}_{\mathbf{6}}$ was chosen as representative for the lanthanides La, Ce, Pr, Nd, Sm, Eu, Gd, Tb, Dy and Ho. From the X-ray crystallographic analysis, $\mathbf{S m L H}_{\mathbf{6}}$ is composed of a Ln(III) which is centred on a two fold axis. Thus the asymmetric unit is half of the complete molecule. The Sm(III)complex crystallizes in the space group $P 6_{1} 22$ and the analysis using SHAPE $^{25}$ shows that the best coordination geometry is Sphenocorona J87 with a deviation value 1.921. The coordination sphere consists of four-coordinating $\mathrm{N}$ atoms and two phenoxo $\mathrm{O}$ atoms of the ligand and four coordinating $\mathrm{O}$ atoms of two bidentate nitrates. Intramolecular hydrogen bonds 
a)

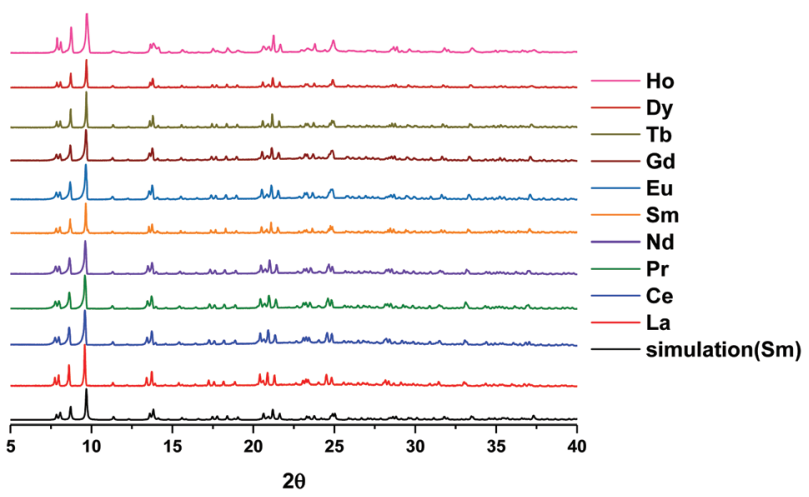

b)

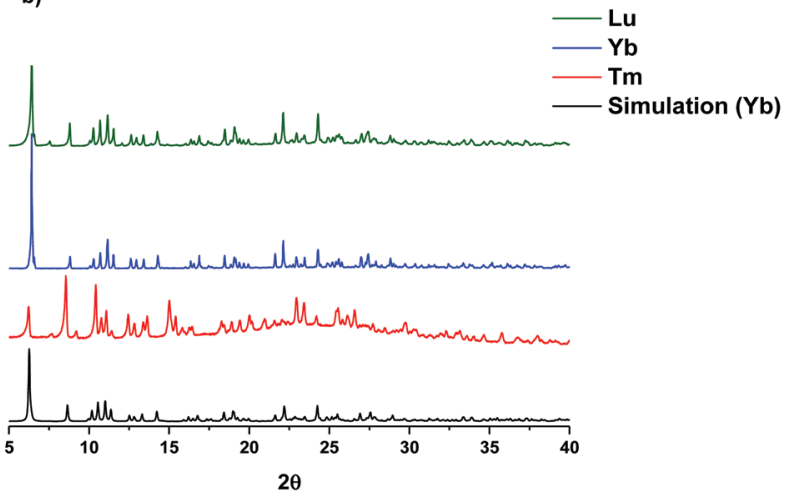

Fig. 4 PXRD of measured $\operatorname{Ln}\left(\right.$ III) $\mathrm{LH}_{6}$ compare to simulation (a) 10 -fold coordination and (b) 8 -fold coordination.

between the phenolate $\mathrm{O} 1$ and the nitrogen back bone amine $\mathrm{N} 1 \mathrm{form}$ through the formal transfer of the phenolate hydrogen to N1. The charge balance is provided by two nitrates, which coordinate to the $\mathrm{Sm}^{3+}$ ion and one nitrate which form intermolecular hydrogen bonds with the N3 and N5 of the ligand. The Sm-O distance ranges from 2.334(2) to 2.584(2) $\AA$, whereas the $\mathrm{Sm}-\mathrm{N}$ distance is between 2.538(3) and 3.000(3) $\AA$.

On the other hand, smaller sized lanthanide metal ions from $\mathrm{Tm}^{3+}$ to $\mathrm{Lu}^{3+}$ represented by the $\mathrm{Yb}$ (III)-complex, which crystallizes in the space group $P \overline{1}$ adopt a triangular dodecahedron geometry with a deviation value 1.911 (SHAPE) through the coordination of four $\mathrm{N}$ atoms and two phenoxo $\mathrm{O}$ atoms of the ligand and two $\mathrm{O}$ atoms from a bidentate nitrate. The charge balance is provided by one nitrate coordinated to $\mathrm{Yb}^{3+}$ and two nitrate counterions which form intermolecular hydrogen bonds with N2, N3 and N8 of the ligand. The Yb-O distance ranges from 2.141(3) to 2.463(4) $\AA$, whereas the $\mathrm{Yb}-\mathrm{N}$ distance is between 2.345(4) and 2.854(4) $\AA$.

The crystallographic parameters and refinement details for $\mathbf{S m L H}_{\mathbf{6}}$ and $\mathbf{Y b L H}_{\mathbf{6}}$ are summarized in Table S1. $\uparrow$ The $\mathbf{E r L H}_{\mathbf{6}}$ is the only complex which crystallizes in the space group $P 2_{1} / c$ and adopts triangular dodecahedron geometry with a deviation value 2.258 (SHAPE) (Fig. 5). The coordination environment of Er(III)-complex is similar to that of the second family with 8 -fold coordination but now the two coordinating oxygen

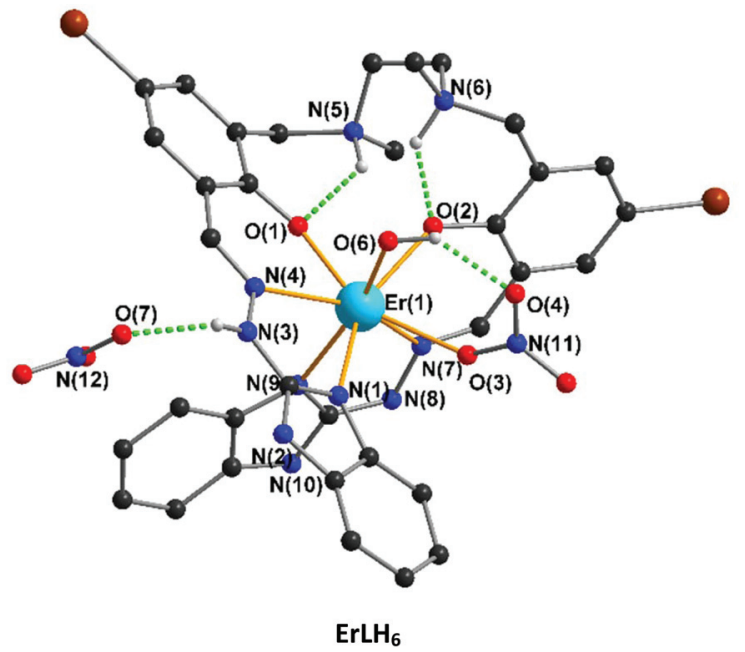

Fig. 5 The structure of $\mathrm{ErLH}_{6}$. Colour codes for the atoms: light blue $(\mathrm{Er})$, blue $(\mathrm{N})$, red $(\mathrm{O})$ black $(\mathrm{C})$ and brown $(\mathrm{Br})$. The hydrogen bond is highlighted in green dashed line. Solvent molecules $(\mathrm{MeCN})$ in lattice and $\mathrm{H}$ atoms are omitted for clarity.

atoms are from $\mathrm{O} 6$ of a water molecule and $\mathrm{O} 3$ of a nitrate. This is reflected by the different space group and powder X-ray pattern (Fig. 6). The crystallographic data for $\mathbf{E r L H}_{\mathbf{6}}$ is summarized in Table S2. $\dagger$

\section{Spectroscopic properties}

IR spectra of $\mathbf{L H}_{\mathbf{6}}$ and the corresponding $\mathbf{L n}(\mathrm{III})$-complexes were measured (see the ESI $\dagger$ ). The broad band of $\nu(\mathrm{OH})$ of phenolic alcohol of the free ligand around $2863-2767 \mathrm{~cm}^{-1}$ disappears when it coordinates to the metal ion. In addition, the sharp bands in the region $1656-1599 \mathrm{~cm}^{-1}$ which can be assigned to the azomethine $\nu(\mathrm{C}=\mathrm{N})$ stretching frequency of the coordinated ligands were found to be shifted to lower frequency in comparison to that of the free ligands $\left(1687-1619 \mathrm{~cm}^{-1}\right)$. This indicates the coordination of the imine nitrogen atom to the metal centre. The other $\nu(\mathrm{C}-\mathrm{H})$, $\nu(\mathrm{C}=\mathrm{C})$ and $\nu(\mathrm{C}-\mathrm{O})$ vibrations are found in the expected ranges from $1465-735 \mathrm{~cm}^{-1}$ (Fig. S5†).

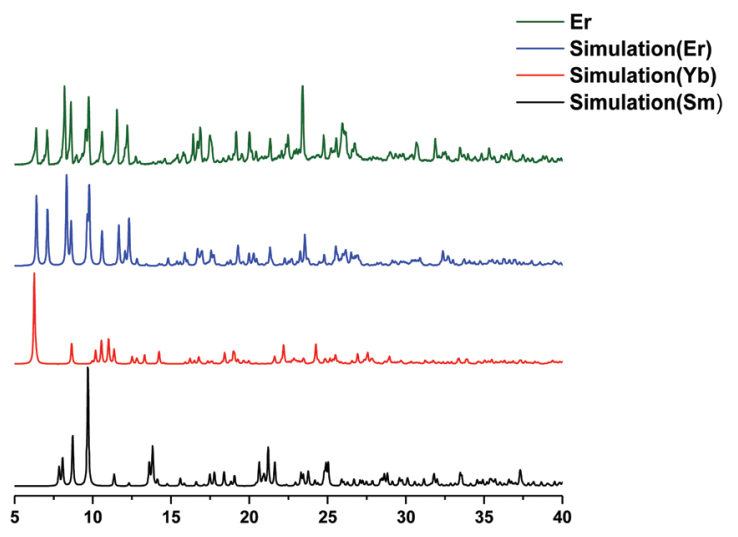

Fig. 6 Comparison of PXRD ErLH 6 with the simulation (Er, Sm, and Yb). 


\section{UV-vis and fluorescence}

The optical properties were investigated using UV-vis and fluorescence spectroscopy. For UV-vis spectroscopy, the absorption maxima at $368 \mathrm{~nm}\left(\mathbf{L a L H}_{\mathbf{6}}\right), 369 \mathrm{~nm}\left(\mathbf{C e L H}_{\mathbf{6}}\right), 375 \mathrm{~nm}\left(\mathbf{G d L H}_{\mathbf{6}}\right)$, $381 \mathrm{~nm}\left(\mathbf{Y b L H}_{\mathbf{6}}\right)$ and $381 \mathrm{~nm}\left(\mathbf{L u L H}_{\mathbf{6}}\right)$ were found to be slightly red shifted from $368 \mathrm{~nm}$ of the free ligand. This can be ascribed to the $\pi-\pi^{*}$ transition of the ligand. In addition, the strong absorption peaks at 286 and $316 \mathrm{~nm}\left(\mathbf{L a L H}_{\mathbf{6}}\right), 284$ and $311 \mathrm{~nm}\left(\mathbf{C e L H}_{\mathbf{6}}\right), 286$ and $320 \mathrm{~nm}\left(\mathbf{G d L H}_{\mathbf{6}}\right), 280$ and $321 \mathrm{~nm}$ $\left(\mathbf{Y b L H}_{\mathbf{6}}\right)$ and 282 and $321 \mathrm{~nm}\left(\mathbf{L u L H}_{\mathbf{6}}\right)$ are related to metal to ligand charge transfer (MLCT) which, of course, are not found in the free ligand. The fluorescence characteristics of these complexes in comparison to $\mathbf{L H}_{\mathbf{6}}$ were measured using an excitation wavelength of $390 \mathrm{~nm}$. The emission maxima at $481 \mathrm{~nm}$ $\left(\mathbf{L a L H}_{\mathbf{6}}\right), 480\left(\mathbf{C e L H}_{\mathbf{6}}\right), 479\left(\mathbf{G d L H}_{\mathbf{6}}\right), 484\left(\mathbf{Y b L H}_{\mathbf{6}}\right)$, and $480 \mathrm{~nm}$

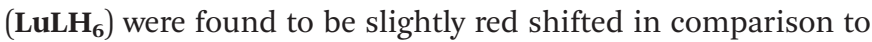
the free ligand at $479 \mathrm{~nm}$. The fluorescence intensity of these complexes were found to be quenched when the free ligand coordinates to lanthanide ions. This optical behaviour reveals the stronger the metal to ligand charge transfer, the weaker the intensity of fluorescence. It is clearly seen that the diamagnetic La(III)-complex shows only $4 \%$ decrease in fluorescence intensity in comparison to the $55 \%$ in the $\mathrm{Yb}(\mathrm{III})$-complex (Fig. 7).
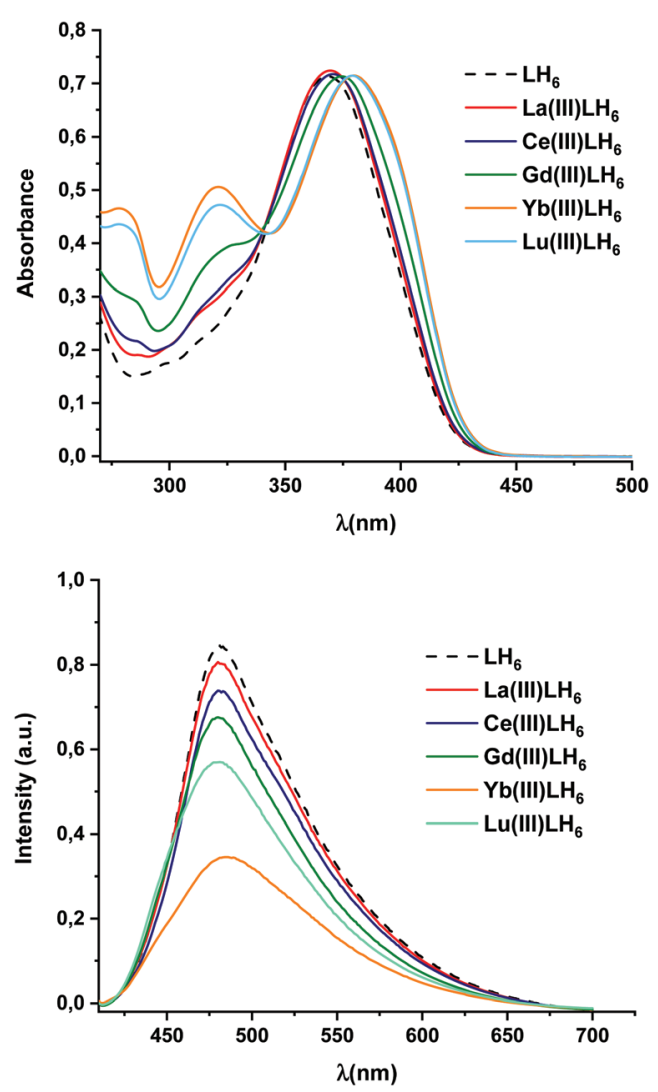

Fig. 7 UV-vis and fluorescence spectra of $\mathrm{LH}_{6}$ compared with $\mathrm{LaLH}_{6}$, $\mathrm{GdLH}_{6}, \mathrm{YbLH}_{6}$ and $\mathrm{LuLH}_{6}$ complexes in $50 \mu \mathrm{M}$ in DMSO $\left(\lambda_{\text {exc }}=390 \mathrm{~nm}\right)$.

\section{Catalytic studies}

The catalytic efficiencies of the series of $\operatorname{Ln}(\mathrm{III})$-complexes and Y(III)-complex (Cat.) for transformation of furfural (3) to trans-4,5dimopholin-2-pentenone (5) were first investigated (Scheme 1). All complexes were used at $1 \mathrm{~mol} \%$ catalytic loading. The reactions were carried out in acetonitrile at room temperature for $2 \mathrm{~h}$. The results reveal that the mononuclear complexes are highly efficient in converting furfural to the target products in high conversion yield as seen from the ratio of ${ }^{1} \mathrm{H}$ signal at 9.67 ppm (aldehyde proton) to the product at $3.29 \mathrm{ppm}$ (trans proton) (Table 1).

The Dy(III)-Cat. shows the maximum conversion yield in comparison to others. Thus, the next step was to evaluate the catalytic properties of the $\mathbf{D} \mathbf{D} \mathbf{L} \mathbf{H}_{\mathbf{6}}$ complex under different reaction conditions. To this end, the time dependency and catalytic loading were investigated. The results show that $\mathbf{D y L H}_{\mathbf{6}}$ at low catalytic loading is highly efficient in transforming biomass furfural to the desired trans-4,5-diaminocyclopentenone adduct in high to quantitative conversion yield (Table 2).

Quantitative yield is achieved after $24 \mathrm{~h}$. However, 98\% can be achieved after $4 \mathrm{~h}$ thus, the condition for $4 \mathrm{~h}$ reaction was used for the extension of catalysis scope (Table 3 ) for the formation of trans-4,5-diaminocyclopentenone using amine derivatives.

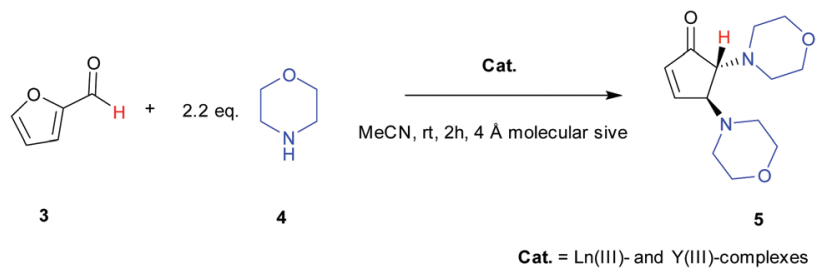

Scheme 1 Catalysis of Ln(III)- and Y(III)-complexes(Cat.) for transformation of furfural (3). The protons followed using NMR are shown in red.

Table 1 Catalytic study of $\operatorname{Ln}(\mathrm{III})-\mathrm{LH}_{6}$ under air exposure for $2 \mathrm{~h}$

\begin{tabular}{lc}
\hline Catalyst & $(\text { Yield })^{a}$ \\
\hline LaLH $_{6}$ & 80 \\
CeLH $_{6}$ & 83 \\
PrLH $_{6}$ & 90 \\
NdLH $_{6}$ & 88 \\
SmLH $_{6}$ & 82 \\
EuLH $_{6}$ & 81 \\
GdLH $_{6}$ & 85 \\
TbLH $_{6}$ & 81 \\
DyLH6 & $95^{b}$ \\
HoLH $_{6}$ & 90 \\
ErLH $_{6}$ & 87 \\
TmLH $_{6}$ & 79 \\
YbLH $_{6}$ & 89 \\
LuLH $_{6}$ & 81 \\
YLH $_{6}$ & 87
\end{tabular}

${ }^{a}$ The conversion yields were determined by the ratio of ${ }^{1} \mathrm{H}$ NMR signal at $9.67 \mathrm{ppm}$ (aldehyde proton) to the product at $3.29 \mathrm{ppm}$ (trans proton). ${ }^{b}$ Highlighting the maximum conversion yield for the Dy(III)Cat. 
Table 2 Catalytic study of DyLH $_{6}$ under air exposure

\begin{tabular}{lll}
\hline Time $(\mathrm{h})$ & 0.5 mol\% $($ Yield \%) & \\
\hline 0.5 & 87 & 1.0 mol\% (Yield) \\
1 & 93 & 91 \\
2 & 95 & 95 \\
4 & 97 & 96 \\
24 & Quantitative & 98 \\
& & Quantitative
\end{tabular}

${ }^{a}$ Followed by ${ }^{1}$ H NMR (see ESI Fig. S38 and S39†).

Table 3 Preparation of trans-4,5-diaminocyclopentenone catalysed by Dy(III)-Cat. under air exposure
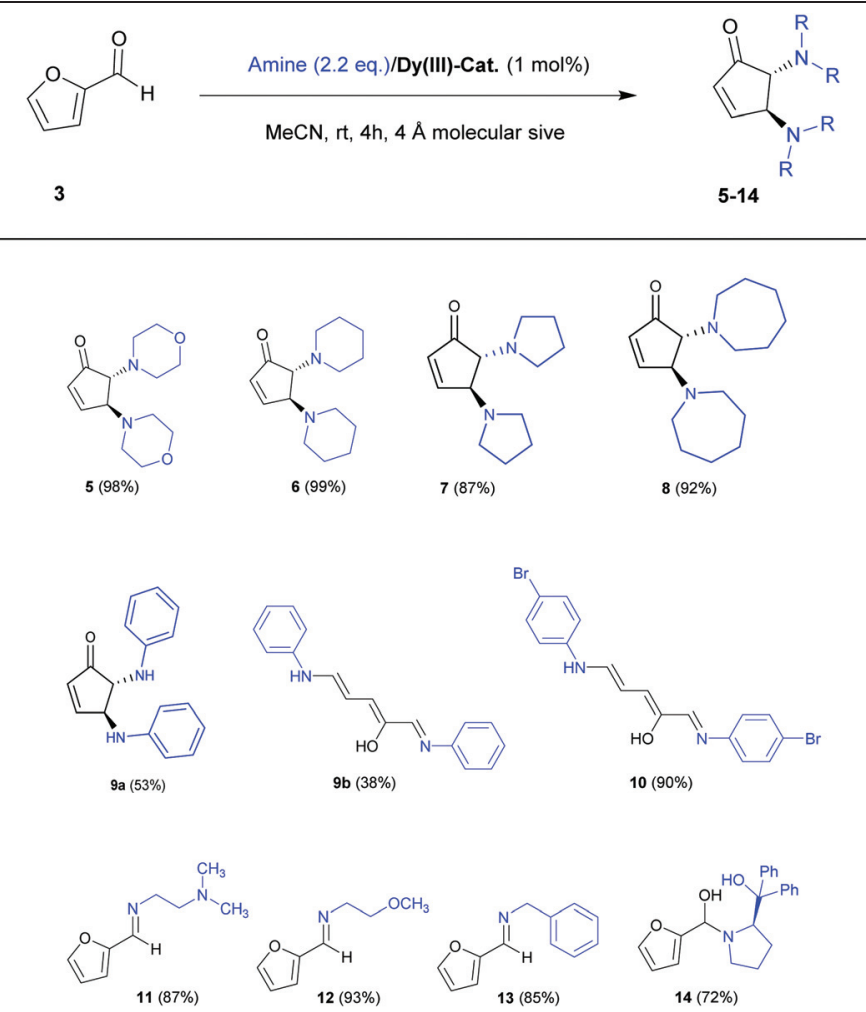

Primary and secondary amine derivatives and also aromatic amines were employed in this study. It is clearly seen that the reaction of furfural with secondary amines gives the trans4,5-diaminocyclopentenone product in high yield (5-8). In addition, when the primary aromatic amine derivatives were used, a mixture of the open and closed form was observed (9a and $9 \mathbf{b}$ ). This can be ascribed to the more stable Stenhouse intermediate formation in the first step (9b) thus it is less likely that the cyclopentenone product will form in the cyclization step. However, protic acid conditions used in the purification step (solvents and silica gel), the desired closed form (9a) product can be obtained. In addition, the reaction of primary aliphatic amine derivatives with furfural under the same reaction conditions was investigated. The expected trans4,5-diaminocyclopentenone products were not achieved unless the imine intermediates were obtained in high yield (com-

\section{Conflicts of interest}

The authors declare no conflict of interest.

\section{Acknowledgements}

pounds 11-14). Nevertheless, this catalytic system can be employed for the transformation of biomass furfural to trans4,5-diaminocyclopentenones in high yield.

This system is attractive because the synthesis of the complexes can be done under mild aerobic conditions in high yields. Furthermore, the almost quantitative catalysis of furfural to the building blocks for natural products synthesis is also achieved under mild aerobic conditions. A further attractive aspect is the fluorescence behaviour of the complexes which could be used in lanthanide sensing.

\section{Conclusions}

The potentially decadentate ligand $\mathbf{L H}_{\mathbf{6}}$ can accommodate 8-fold and 10-fold coordinate single ion lanthanum to lutetium and yttrium complexes. Crystalline products were obtained in high yield after 7 days under aerobic conditions. Moreover, the powder product can be directly obtained in higher yield after vigorously stirring for $2 \mathrm{~h}$. The optical behaviour of these complexes, for instance the metal to ligand charge transfer process, was reflected by the increase in absorption intensity at $280 \mathrm{~nm}$ and $321 \mathrm{~nm}$ from UV-vis and the decrease in fluorescence intensities in comparison to the free ligand, making this a candidate for metal fluorescence sensors. The catalytic study reveals high efficiency and the amount of catalysts can be reduced to $0.5 \mathrm{~mol} \%$ loading without loss of activity. Furthermore, the efficient $4 \mathrm{~h}$ reaction time could be applied to a range of amines with over $90 \%$ yield. This is thus a promising catalytic system for transforming furfural which also shows fluorescence properties.

We thank the DFG for funding through SFB/TRR 88 "3MET" and the Helmholtz Foundation POF STN.

\section{References}

1 T. Y. Chiu, W. Chin, J. R. Guo, C. F. Liang and P. H. Lin, Chem. - Asian J., 2019, 14, 627-633.

2 X. Xia, C. Lu, B. Zhao and Y. Yao, RSC Adv., 2019, 9, 1374913756.

3 Y. Xie, C. Lu, B. Zhao, Q. Wang and Y. Yao, J. Org. Chem., 2019, 84, 1951-1958.

4 C. Lu, L. Hu, B. Zhao and Y. Yao, Organometallics, 2019, 38, 2167-2173.

5 L. Daumann, Angew. Chem., Int. Ed., 2019, 58, 1279512802. 
6 S. W. Li and R. A. Batey, Chem. Commun., 2007, 8, 37593761.

7 L. Sanzhong, Z. Baolian, X. Ming, A. Jañczuk, X. Wenhua, C. Jinpei and P. G. Wang, Chin. Sci. Bull., 2008, 46, 16731681.

8 G. K. Veits, D. R. Wenz and J. Read De Alaniz, Angew. Chem., Int. Ed., 2010, 49, 9484-9487.

9 L. I. Palmer and J. Read De Alaniz, Angew. Chem., Int. Ed., 2011, 50, 7167-7170.

10 A. Procopio, P. Costanzo, M. Curini, M. Nardi, M. Oliverio and G. Sindona, ACS Sustainable Chem. Eng., 2013, 1, 541544.

11 A. Hiscox, K. Ribeiro and R. A. Batey, Org. Lett., 2018, 20, 6668-6672.

12 P. A. Duspara and R. A. Batey, Angew. Chem., Int. Ed., 2013, 52, 10862-10866.

13 J. J. Bozell and G. R. Petersen, Green Chem., 2010, 12, 539554.

14 M. M. Domostoj, E. Irving, F. Scheinmann and K. J. Hale, Org. Lett., 2004, 6, 2615-2618.

15 F. A. Davis and J. Deng, Org. Lett., 2005, 7, 621-623.

16 D. Ramesh, T. S. Reddy, M. Narasimhulu, S. Rajaram, N. Suryakiran, K. C. Mahesh and Y. Venkateswarlu, Chem. Lett., 2009, 38, 586-587.
17 J. Liu, J. Yu, M. Zhu, J. Li, X. Zheng and L. Wang, Synthesis, 2013, 45, 2165-2170.

18 J. P. M. Nunes, C. A. M. Afonso and S. Caddick, RSC Adv., 2013, 3, 14975-14978.

19 K. Griffiths, C. W. D. Gallop, A. Abdul-Sada, A. Vargas, O. Navarro and G. E. Kostakis, Chem. -Eur. J., 2015, 21, 6358-6361.

20 K. Griffiths, P. Kumar, J. D. Mattock, A. Abdul-Sada, M. B. Pitak, S. J. Coles, O. Navarro, A. Vargas and G. E. Kostakis, Inorg. Chem., 2016, 55, 6988-6994.

21 M. S. Estevão and C. A. M. Afonso, Tetrahedron Lett., 2017, 58, 302-304.

22 M. Nardi, P. Costanzo, A. De Nino, M. L. Di Gioia, F. Olivito, G. Sindona and A. Procopio, Green Chem., 2017, 19, 5403-5411.

23 R. F. A. Gomes, N. R. Esteves, J. A. S. Coelho and C. A. M. Afonso, J. Org. Chem., 2018, 83, 7509-7513.

24 Y. Masami, M. Yukiko, O. Masaaki and O. Hisashi, Chem. Lett., 1996, 25, 601-602.

25 P. Llunell, M. Casanova, D. Cirera, J. Alvarez and S. Alemany, SHAPE: Program for the Stereochemical Analysis of Molecular Fragments by Means of Continuous Shape Measures and Associated Tools, version 2.1, Universitat de Barcelona, Barcelona, 2013. 